\title{
Membangun Karakter Anak Bangsa Melalui Pendidikan Islam Dan Keluarga
}

\author{
Dian Mohamad Anwar \\ Program Studi Komputerisasi Akuntansi, Universitas Bina Sarana Informatika \\ dian.dmn@bsi.ac.id
}

Cara Sitasi: Anwar. D. M. (2019). Membangun Karakter Anak Bangsa Melalui Pendidikan Islam Dan Keluarga. Cakrawala, 19(2), 243-248. Retrieved from doi: https://doi.org/10.31294/jc.v19i2

\begin{abstract}
This research discusses about the importance of Islamic education and education in the family. This study is important because in the development of the progress and characteristics of a country must be supported by the quality of the character and morals of its people, in this case especially teenagers as the heir to the leadership baton and the progress of the Indonesian state. This study discusses how Islamic education and the family are able to shape the character of the nation's children who are intelligent, character and moral. The method used in this research is descriptive analytic method that is by describing the concepts of education and psychology experts about character education, the concept of Islamic education and the concept of the role of parents in the family. The author then analyzes to find the correlation between the concepts that exist in the process of character formation. The results obtained can be concluded that religious education and family education in this case parents have an important role in shaping the character of the nation's children. Islamic religious education directs every human being to positive behavior and character, and the concept of the role of parents in family education plays a large role as a rule model in the process of habituation for the application of Islamic education, both of which are inseparable components to be able to build positive character traits of the nation's children smart and religious.
\end{abstract}

Keywords: Character, Islamic Education, Family

\section{PENDAHULUAN}

Negara Indonesia adalah sebuah negara yang sangat besar dan luas dengan jumlah penduduk terbanyak nomor 4 didunia (economy.okezone.com) dengan kemajemukan sosial budaya yang beraneka ragam. Karenanya bangsa Indonesia memiliki modal dan peluang yang sangat besar untuk menjadi negara yang maju, berdaulat, bermartabat, adil dan makmur.

Kemajuan dan karakteristik suatu negara dan bangsa yang maju dan bernilai positif disetiap lini kehidupan masyarakat harus ditopang dengan kualitas karakter dan moral rakyatnya. Semakin buruk moral suatu bangsa walaupun itu adalah negara maju maka akan semakin hancur dan terpuruk negara tersebut dan semakin baik kualitas moral suatu negara walau negara tersebut adalah negara yang sedang berkembang, maka negara itu akan menjadi suatu negara yang maju dan berperadaban tinggi dengan kualitas terbaik. Hal itu bisa dilihat dari sejarah Andalusia diabad ke 7 sampai abad 13 di saat pendidikan dan nilai-nilai islam diterapkan di dalam keluarga dan masyarakat sebagai perekat universal dengan saling menghargai serta nilai toleransi yang telah diajarkan oleh rasulullah dan sahabatsahabatnya, maka Andalusia yang saat itu terjajah akhirnya berubah menjadi negara adidaya yang maju pesat dan menjadi referensi pertama dalam kemoderenisasian ilmu pengetahuan dan teknologi sampai saat ini.
Sejarah Andalusia adalah kisah tentang kegemilangan kaum muslim yang berhasil menaklukkan wilayah benua eropa yang kemudian mengisinya dengan tinta emas kejayaan dan keunggulan perdabannya. Jejak-jejak kecemerlangan peradaban kaum muslim menjadi rujukan bangsabangsa eropa. Banyak ilmuan dan ulama yang ahli dalam berbagai bidang, yang kemudian menjadi pionir ilmu pengetahuan serta menjadi acuan ilmuwan-ilmuan barat sampai kurang lebih 800 tahun lamanya. (As-Sirjani, 2013)

Seiring dengan perkembangan waktu dan semakin memudarnya nilai-nilai Islam dam perilaku berbangsa dan bernengara diwilayah Andalusia (saat ini bernama spanyol), dan setiap orang dalam keluarga sudah mengurusi egonya masing-masing dan tidak ada kepedulian satu dengan yang lain, maka mulailah negara tersebut menjadi hancur luluh lantah. Kemajuan dan karakteristik ajaran Islam dan kebudayaannya hanya tinggal sejarah sampai saat ini. Keruntuhan sebuah peradaban suatu negara ditandai dengan semakin lunturnya nilai-nilai agamis dan hilangnya karakter diri serta kebudayaan yang bernilai positif walaupun keberadaan bangsa tersebut masih ada secara eksis dan di akui.

Begitu juga dengan kondisi Indonesia yang dulu begitu agamis, damai, aman, tentram, selalu terdengar suara orang yang mengaji membaca alqur'an selepas shalat maghrib dan penuh kebaikan 
dalam tiap kehidupan yang ada, sekarang menjadi suatu bangsa yang begitu mengundangan keprihatinan yang mendalam. Dimulai dari maraknya pergaulan bebas, narkoba, korupsi, peredaran video porno, sex bebas yang menjangkiti pergaulan remaja, bullying di dunia pendidikan saat masa orientasi, games online yang marak dengan kekerasan dan aksi porno,dan lain sebagainya yang secara langsung maupun tak langsung bagi anak-anak bangsa sedikit banyak memberikan pengaruh negative terhadap hasil pendidikan mereka sebagai asset masa depan bangsa. Kenyataan tersebut sangat menyesakkan dada dan seolah mengiris hati setiap orang yang mengetahuinya. Kondisi seperti ini yang harus menutut setiap orang di negara Indonesia harus memberikan perhatian lebih pada pendidikan karakter anak bangsa.

Dampak negatif ini sebenarnya masih dapat ditangani bila anak bangsa memiliki ketahanan mental yang cukup yang berasal dari pondasi agama, moral dan budaya yang kuat. Ketahanan mental ini yang akan membentuk karakter positif yang kuat bagi anak bangsa.

Terminologi pendidikan karakter mulai ramai dibicarakan didunia barat sejak tahun 90an. Thomas Lickona melalui karyanya "the return Of Character Education" memberikan kesadaran pada dunia pendidikan bahwa pendidikan karakter adalah konsep yang harus digunakan dalam kehidupan manusia dan sejak saat itulah kebangkitan pendidikan karakter menjadi lebih dikembangkan oleh banyak orang (Majid \& Handayani, 2012)

Membangun Indonesia menjadi negara dan bangsa yang maju adalah impian setiap orang yang cinta dengan negara ini, dan salah satu faktor yang paling menentukan adalah generasi mudanya yang harus dioptimalkan baik secara intelektual, emosional dan spiritualnya. Dan tentunya ini memerlukan banyak bantuan dan peran serta pemerintah Indonesia, masyarakat, organisasi pemuda, lembaga dakwah, dan institusi pendidikan perguruan tinggi salah satunya adalah kampus Universitas BSI yang memiliki target dalam mengembangkan generasi Indonesia yang berilmu pengetahuan, berteknologi tinggi dan memiliki karakter positif untuk setiap lulusannya.

Pemuda adalah pewaris tongkat estafet kepemimpinan dan kemajuan negara Indonesia yang sangat perlu diperhatikan dan dibina dengan maksimal. Tolak ukur keberhasilan suatu negara dimasa mendatang diawali dengan keberhasilan generasi muda yang cerdas, berkarakter dan berakhlak yang merupakan peringkat yang menentukan dalam bangunan suatu umat, bangsa dan negara (As-Sirjani, 2016).

Bangsa Indonesia mempertaruhkan kehidupan negara ini di tangan anak-anak bangsa dengan karakter yang kini mereka miliki. Oleh karena itu, pendidikan karakter yang berkesinambungan, terarah dan bertahap menjadi sangat penting sebagai bagian dari usaha untuk mempersiapkan mereka menjadi generasi penerus bangsa yang kompetitif selain pendidikan agama dan peran serta keluarga sangat diperlukan.

Negara Indonesia akan seperti apa masa depannya dapat dilihat dari seberapa bagus kualitas anak bangsanya. Dalam hal ini khususnya para pemuda yang harus mampu mengembangkan kemampuan diri dengan skill, teknologi, pembentukan karakter diri dan pendidikan agama sehingga Indonesia memiliki prinsip dan jati diri tanpa harus terombang ambing dengan masalah dan terbawa arus tantangan akhir zaman yang semakin buruk.

Dunia yang semakin mengglobal di era digital ini memunculkan sebuah fenomena bahwa hubungan manusia sudah mendunia dengan sangat cepat yang ditandai dengan minimnya batas negara secara teknologi. Era Globalisasi yang kebablasan bisa jadi akan sangat banyak membawa pengaruh dalam mengikis moral \& akhlaq anak bangsa zaman now sehingga dengan sangat mudah mengikuti tren-tren yang ada tanpa disaring terlebih dahulu, selain juga bisa jadi mampu menggulung karakter bangsa dan budaya suatu negara yang mampu mengubah tata nilai dan cara pandang seseorang dalam mensikapi sesuatu yang sedang terjadi.

Melihat kondisi diatas maka perlu disiapkan generasi muda anak bangsa yang berjiwa nasionalis dan patriotis, cerdas dan religious melalui pendidikan karakter Islami yang mampu menjunjung tinggi nilainilai norma, etika dan budaya sebuah bangsa dan negara. Sehubungan dengan hal tersebut, maka tulisan ini layak dijadikan acuan untuk mengulas pembangunan karakter anak bangsa melalui pendidikan Islam dan keluarga

\section{a. Pendidikan Karakter Bangsa}

Pendidikan sebagai proses humanisasi lebih menitikberatkan kepada peran manusia sebagai makhluk sosial yang memiliki otonomi moral dan sensivitas budaya. Artinya bahwa manusia sebagai makhluk individu sekaligus sebagai makhluk sosial harus bisa dan mampu mengelola konflik serta menghargai kemajemukan berbagai budaya.

Tantangan globalisasi dan proses demokrasi yang semakin kuat dan beragam disatu pihak, dan dunia pendidikan sepertinya lebih mementingkan penguasaan dimensi pengetahuan (kognitif) saja dan mengabaikan pendidikan nilai/moral (afektif), merupakan alasan yang kuat bagi bangsa Indonesia untuk membangkitkan komitmen dan melakukan pendidikan karakter berdasarkan panduan agama. Pendidikan karakter bangsa yang religious diharapkan mampu menjadi alternatif solusi untuk mengatasi berbagai persoalan.

Efek negatif kemajuan teknologi dan era globalisasi tampaknya menuntut pendidikan karakter 
perlu ditransformasikan sejak dini, yakni sejak pendidikan anak usia dini, pendidikan dasar, pendidikan menengah dan pendidikan tinggi secara holistik dan berkesinambungan.

Mengapa pembentukan karakter harus dari sejak usia dini?, Para ahli pendidikan dan psikologi berpendapat bahwa tahapan-tahapan awal kehidupan seorang anak merupakan masa yang sangat penting untuk meletakkan dasar-dasar kepribadian yang akan memberi warna ketika ia menjadi dewasa (Rosadi, 2013).

Seperti yang dikatakan oleh Montessori bahwa otak anak ibarat sponge kering, apabila dicelupkan kedalam air akan mampu menyerap air dengan sangat cepat. Apabila yang diserap adalah air bagus, maka baguslah ia dan sebaliknya (Zubaedi, 2017).

Perilaku manusia dikendalikan oleh peranan otak. Perilaku yang tidak baik seperti yang dilakukan oleh sebagian anak muda bangsa Indonesia saat-saat ini menandakan bahwa pikiran yang ada dalam otak mereka adalah hal-hal yang tidak baik. Oleh karena itu, pendidikan karakter dalam membentuk akhlaq mulia sejak usia dini mutlak diperlukan, karena apabila usia anak sudah besar akan sulit diubah karena masa tercepat pertumbuhan struktur otak sudah terlewati.

Pendidikan karakter kini memang sudah menjadi wacana utama pendidikan nasional. Bertepatan dengan hari pendidikan nasional pada bulan mei 2010, mentri pendidikan telah mencanangkan penerapan pendidikan karakter di seluruh jenjang pendidikan.

Pendidikan nasional berfungsi mengembangkan kemampuan dan membentuk watak serta peradaban bangsa yang bermartabat dalam rangka mencerdaskan kehidupan bangsa, bertujuan untuk berkembangnya potensi peserta didik agar menjadi manusia yang beriman dan bertakwa kepada Tuhan Yang Maha Esa, berakhlak mulia, sehat, berilmu, cakap kreatif, mandiri, dan menjadi warga negara yang demokrasi serta bertanggung jawab. (Kurniawan, 2013).

Salah satu aspek penting dalam pendidikan karakter adalah proses pembentukan kepribadian. Tujuan pendidikan karakter adalah memunculkan kepribadian dan sikap hidup yang lebih baik pada setiap anak bangsa. Karakter yang terintegral dalam kepribadian akan terbentuk melalui proses yang bertahap dan berkesinambungan, dimulai dari penanaman nilai, munculnya sikap dan prilaku , terbentuk karakter kemudian terbentuknya kepribadian.

Karakter seseorang adalah nilai yang ada di dalam diri yang bukan watak bawaan. Proses membangun sebuah karakter adalah proses penanaman nilai pada diri seseorang sehingga ia benar-benar menjadi sifat yang menetap dalam jiwa (Sodiq, 2018).
Konsep karakter dalam kajian modern sebenarnya memiliki kaitan yang sangat erat dengan persoalan akhlaq dalam pendidikan Islam yaitu pada persoalan penanaman nilai sehingga menjadi sikap yang menetap. Nilai-nilai yang menetap pada tiap pribadi dalam islam bukanlah sembarang nilai, tetapi nilai yang ada didalam Al-Qur'an, hadist dan nilai yang tertanam dalam pribadi rasulullah SAW yang harus menjadi acuan dalam pendidikan karakter.

Akhirnya kita berharap bahwa proses pembentukan akhlaq dengan proses pendidikan karakter ini mampu menjawab tantangan Indonesia dimasa yang akan datang dengan munculnya pemimpin masyarakat dan pemerintah dari anak bangsa yang memiliki karakter yang baik.

\section{b. Pendidikan Islam sebagai Pendidikan Karakter}

Anak bangsa saat ini hidup pada zaman dengan kondisi ilmu pengetahuan dan kebebasan teknologi yang sangat tinggi yang mampu mengubah sendi-sendi budaya dan kehidupan sosial masyarakat bangsa secara fundamental. Durasi perubahan besar dalam kehidupan berlangsung sangat cepat karena faktor-faktor pengubahnya bekerja simultan dan cepat seperti kilat yang berefek timbulnya disorientasi dalam dunia pendidikan dan sosial bermasyarakat sehingga mampu mengubah karakter suatu bangsa jika tidak cepat dikendalikan.

Cepatnya faktor pengubah sendi-sendi kehidupan dalam bangsa terlihat dengan banyaknya orang dalam masyarakat khususnya orang tua yang tidak punya kendali atas zaman yang kelak akan dilalui anak bangsa ke depan. Bahkan bisa jadi sebagai orang tua sudah tiada disaat mereka mengalami perubahan-perunahan besar itu. Melihat begitu cepatnya perubahan dalam kehidupan , maka anak bangsa membutuhkan pegangan hidup yang bersifat permanen yang tidak ikut berubah dalam perubahan-perubahan itu, yaitu keyakinan dan nilainilai agama Islam. Agama Islam mengajarkan kepada manusia tentang hakikat besar kehidupan, tentang asal usul mereka, tujuan hidup, dan nilai-nilai yang harus dipegang dalam menjalani kehidupan. Apabila anak bangsa memahami semua itu dengan benar, maka akan tumbuh dalam kehidupan yang maju berperadaban tinggi dengan nilai moral dan etika yang bagus.

Pendidikan Islam merupakan salah satu pilar pendidikan karakter yang paling utama. Pendidikan karakter akan tumbuh dengan baik jika dimulai dari tertanamnya jiwa keberagamaan pada anak. Dalam Islam terdapat nilai utama, yaitu akhlak, adab dan keteladanan. Akhlaq merujuk kepada tugas dan tanggung jawab selain syari'ah dan ajaran agama secara umum. Sedangkan term adab merujuk kepada sikap yang dihubungkan dengan tingkah laku yang baik. Dan keteladanan merujuk kepada kualitas karakter yang ditampilkan oleh seorang yang baik 
yang mengikuti keteladanan Nabi Muhammad Saw. ketiga nilai ini yang menjadi pilar pendidikan karakter dalam Islam.

Pendidikan akhlaq merupakan salah satu dimensi penting dalam Pendidikan Islam. namun perlu dipahami bahwa pendidikan akhlaq dalam Islam lebih mulia dibanding dengan pendidikan karakter secara umum, karena akhlaq memiliki dimensi ilahiyah sedangkan karakter hanya berbicara pada lingkup baik dan buruk menurut manusia tanpa perlu menyertakan Tuhan (Tafsir, 2016).

Terlepas adanya perbedaan konsep antara karakter dengan akhlaq, agar terjadi kombinasi yang saling terhubung dalam menciptakan generasi yang berkualitas maka diperlukan gabungan keduanya yaitu pendidikan karakter berbasis al-quran dan sunnah.

Pendidikan Islam memang memiliki hubungan yang sangat erat dan mendalam dengan ilmu psikologi dalam soal pendidikan karakter dan pembinaan mental. Islam menggunakan istilah Akhlaq untuk mengekspresikan karakter manusia. Sebagaimana sabda Rasulullah SAW :

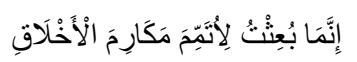

Artinya : Sesungguhnya tiada aku di utus melainkan untuk menyempurnakan Akhlaq (H.R. AlBaihaqi).

Dalam pandangan Islam, akhlak memang merupakan satu-satunya ukuran dan menjadi garis pemisah antara perbuatan baik perbuatan buruk. Artinya, prilaku manusia disebut berkualitas, jika prilaku tersebut disertai dengan akhlak yang baik, sebaliknya jika suatu perbuatan tidak dibarengi dengan akhlak baik, maka perbuatan itu merupakan perbuatan yang hina dan tidak berkualitas.

Sehingga jika ditinjau dari sisi pendidikan, tidak dapat dipungkiri bahwa pendidikan akhlaq merupakan prasyarat keberhasilan pendidikan lainnya, dan dari sisi social maka pendidikan karakter dalam hal ini akhlaq berperan penting dalam membangun kehidupan berkeluarga, bermasyarakat, berbangsa dan bernegara.

\section{c. Pendidikan Keluarga dan Pembentukan Karakter}

Pengembangan karakter positif sangatlah penting karena karakter adalah kualitas yang dibawa oleh seseorang yang akan membedakannya dengan orang lain (Darta, 2017). Karakter positif haruslah mampu dikembangkan khususnya oleh orang tua dalam keluarga karena orang tua adalah bagian dari keluarga yang paling dekat dengan anak-anakanya.

Lingkungan keluarga adalah lingkungan pertama yang dikenal oleh anak. Sebelum anak mengenal lingkungan di sekolah, kampus, dan masyarakatnya, mereka terlebih dahulu belajar segala hal dari keluarganya. Didalam keluarga, Orang tua adalah merupakan komunitas pertama yang ditemui anak semenjak dilahirkan. Pendidikan dan pengasuhan orang tua memberikan pengaruh yang besar dalam membentuk kepribadian anak. orang tualah yang pertama kali memperkenalkan anak kepada nilai-nilai moral kehidupan. Orang tua juga sebagai role model untuk anak bagaimana anak dapat berinteraksi dalam kehidupan.

Anak adalah amanah dari Allah SWT dimana orang tua memiliki kewajiban penuh dalam mempersiapkan anak menjalani kehidupan dan melindunginya dari kehinaan serta mengarahkan agar tumbuh menjadi Insan manusia yang berakhlak terpuji. Anak haruslah dibiasakan dan diajarkan untuk melakukan kebaikan, maka niscaya tingkah laku anak akan terbentuk baik dan terdidik. Bentuk ikhtiar orang tua juga adalah mendidiknya dengan ilmu pengetahuan dan agama agar tidak menjadi lemah dan tidak menjadi fitnah dan cobaan.

Keluarga yang harmonis adalah keluarga yang seluruh anggotanya merasa satu. Hubungan yang diliputi saling mengasihi, kerjasama dan saling memahami, menunjang perkembangan rasa kasih sayang dalam diri anak-anaknya. Dalam persepektif Islam secara tegas dikatakan bahwa pendidikan akhlaq anak adalah tanggung jawab orang tua, dan kelak orang tua akan dimintakan pertanggung jawabannya dihadapan Allah SWT kelak dihari akhir.

Keberhasilan pendidikan akhlaq dan karakter anak bangsa menuntut adanya pendidikan yang menggunakan pendekatan psikologi dan berpedoman pada nilai-nilai Islam sehingga harapan, tujuan dan metode pendidikan mengarahkan terbentuknya akhlaq mulia, dan karakter yang baik yang berbudi pekerti luhur.

\section{METODOLOGI PENELITIAN}

Metode yang digunakan dalam penelitian ini adalah metode deskriptif analitik yaitu sebagai suatu cara bagaimana suatu data ditampilkan agar informasi yang ditampilkan dapat secara jelas diterima oleh orang lain.

Metode deskriptif analitik dalam tulisan ini digunakan dengan mengambil kondisi dan keadaan yang ada dimasyarakat dikombinasi dengan konsep teori para ahli pendidikan dan pakar psikologi tentang pendidikan karakter, teori pendidikan Islam dalam membentuk akhlaq yang mulia dan konsep peranan orang tua dalam keluarga untuk mendidikan anak bangsa sehingga memiliki kakarter yang baik

Penulis kemudian menganalisis beberapa konsep diatas untuk menemukan korelasinya dalam proses pembentukan karakter dan akhlaq anak bangsa, sehingga diharapkan mampu menjawab tantangan dimasa yang akan datang tentang kondisi Indonesia yang lebih baik dari sekarang, menjadi negara yang maju dengan pemimpin dan masyarakat yang berkarakter mulia. 


\section{HASIL PENELITIAN}

Tantangan zaman yang semakin berat di era globalisasi dan teknologi modern yang kebablasan ditambah lagi fenomena negatif kehidupan dan kriminalitas yang terjadi di Indonesia disebabkan karena krisisnya pendidikan karakter bangsa Indonesia dan pendidikan agama yang mulai diremehkan dan tidak lagi menjadi pendidikan yang utama, sehingga tatanan sosial masyarakat semakin menjadi bobrok dan rusak. maraknya pergaulan bebas, narkoba, korupsi, dan lain sebagainya sedikit banyak telah memberikan pengaruh negatif terhadap hasil pendidikan mereka sebagai asset masa depan bangsa.

Karakter merupakan tema sentral dalam upaya peningkatan sumber daya manusia di segala bidang kehidupan pribadi, masyarakat, bangsa dan negara. Keberhasilan pembangunan Indonesia ditentukan oleh kualitas karakter bangsa Indonesia. Kualitas generasi penerus bangsa amat berperan dalam menentukan kualitas bangsa Indonesia mendatang.

Pendidikan karakter yang baik tidak semudah membalikkan telapak tangan. Anak bangsa seringkali terpengaruh oleh lingkungan yang kurang baik. Karenanya haruslah ada pembinaan karakter yang bernilai religi melalui konsep pendidikan Islam disetiap lingkungan masyarakat.

Konsep pendidikan karakter yang islami adalah menanamkan nilai-nilai ilahiyah dan nubuwwah dalam mencetak manusia menjadi sosok insan kamil yang memiliki karakter yang spiritualis. Melalui panduan kitab suci alquran dan hadist, kehadiran manusia sebagai khalifah dimuka bumi benar-benar teraplikasi dalam kehidupan yang memiliki karakter mulia, dan membawa manusia dalam kehidupan yang bahagia di dunia dan selamat di akhirat.

Adapan Keluarga adalah sekolah pertama bagi setiap anak bangsa, dimana didalamnya setiap anak akan belajar tentang kasih sayang, kebaikan, saling menghormati, pengorbanan yang positif, kedisiplinan dan keimanan pada Dzat yang Maha Tinggi yaitu Allah SWT, sehingga dapat dikatakan bahwa keluarga adalah pondasi awal untuk pendidikan akhlaq atau moral yang melandasi semua bangunan sosial dimasyarakat.

Berkaitan dengan pembentukan karakter, Diperlukan kerjasama dan kemitraan yang sangat efektif antara pemerintah, masyarakat, lembaga agama dan pendidikan, juga keluarga dalam membangun pendidikan karakter kepada anak bangsa. Dan pendidikan keluarga adalah yang paling dominan pengaruhnya. Jika suatu rumah tangga berhasil membangun karakter yang islami maka peran masyarakat dan sekolah hanya menjadi pelengkap saja. Wallahu'alam.

\section{KESIMPULAN}

Karakter merupakan tema sentral dalam upaya peningkatan sumber daya manusia di segala bidang kehidupan pribadi, masyarakat, bangsa dan negara. Keberhasilan pembangunan Indonesia ditentukan oleh kualitas karakter bangsa Indonesia. Kualitas generasi penerus bangsa amat berperan dalam menentukan kualitas bangsa Indonesia mendatang. Pendidikan karakter yang baik tidak semudah membalikkan telapak tangan. Anak bangsa seringkali terpengaruh oleh lingkungan yang kurang baik. Karenanya haruslah ada pembinaan karakter yang bernilai religi melalui konsep pendidikan Islam disetiap lingkungan masyarakat.

\section{REFERENSI}

Ahmad Tafsir. (2016). Pendidikan Karakter Berbasis Wahyu. Ciputat: Gaung Persada

Akhmad Sodiq. (2018). Prophetic Character Building. Jakarta: Kencana

Hanny Mukhtar Darta. (2017). Positive Characters with Parenting (Untuk Orang Tua Dengan Anak Usia 0-12 Tahun). Jakarta: Elex Media Computindo

https://economy.okezone.com/read/2018/07/21/320/1 925559/indonesia-penduduk-terbanyak-nomor4-di-dunia-siapa-juaranya. Diunduh hari, senin 18 Februari 2019

Majid, A. \& Andayani, D. (2012). Pendidikan Karakter Perspektif Islam. Bandung: Remaja Rosdakarya.

Raghib As-Sirjani. (2013). Bangkit dan Runtuhnya Andalusia. Jakarta: Pustaka Al-Kautsar.

Raghib As-Sirjani. (2016). Sumbangan Peradaban Islam pada Dunia. Jakarta: Pustaka Al-Kautsar.

Rahmat Rosyadi. (2013). Pendidikan Islam Dalam Pembentukan Karakter Anak Usia Dini (konsep dan Praktik PAUD Islam). Jakarta: Rajawali

Yudha Kurniawan \& Tri Puji Hindarsih. (2013). Character Building (Membangun Karakter Menjadi Pemimpin). Yogyakarta: Pro-U Media

Zubaedi. (2017). Strategi Taktis Pendidikan Karakter (Untuk Paud dan Sekolah). Depok: Rajawali Pers. 
